\title{
Interpretação sistêmica e sustentabilidade jurídica: A necessária (re) construção do Direito do Trabalho
}

\author{
Systemic interpretation and legal sustainability: \\ The need of (re) construction of Labor Law
}

\author{
Denise Pires Fincato \\ Pontifícia Universidade Católica do Rio Grande do Sul, Brasil \\ Jaqueline Mielke Silva \\ Fundação Escola da Magistratura do Rio Grande do Sul \\ y Escola Superior da Magistratura Federal, Brasil
}

\begin{abstract}
RESUMO Texto percorre as transformações socioculturais dos últimos séculos, especialmente observando a evolução tecnológica no cenário das relações de trabalho. Localiza a problemática na transposição da Modernidade para a Pós-Modernidade e analisa a pertinência do arcabouço normativo trabalhista brasileiro (moderno) à realidade do trabalho globalizado, digital e flexisseguro (pós-moderno). Visita os conceitos e usos da interpretação jurídica sistemática em contraposição à sistêmica, na qual se detém. Conclui que: i) o Direito do Trabalho brasileiro carece de adequação à realidade que pretende reger, o que será possível alcançar pela via interpretativa, desde que o operador maneje as ferramentas próprias do método sistêmico; e que ii) tal providência é necessária à manutenção e sustentabilidade do próprio ramo especializado do direito, pois a distância da realidade, mesmo que complexa e dinâmica, torna-o sem sentido.
\end{abstract}

PALAVRAS-CHAVE Interpretação sistêmica, direito do trabalho, sustentabilidade.

ABSTRACT The text analizes the socio-cultural transformations of the last centuries, especially observing the technological evolution in the labor relations scenario. It points out the issues in the transposition from Modernity to the Post-Modernity and analyzes the Brazilian labor framework normative (modern) comparing it to the globalized work, digital and «flexisseguro» (postmodern). It also goes through the concepts and uses of systematic legal interpretation opposed to the systemic method in which it stands. It concludes that (i) Brazilian Labor Law lacks of reality it intents do rule, which can be reached by the interpretative path, since the operator handles the right tools of the systemic method, (ii) and such deliberation is necessary to the sustainability and admin- 
istration of the specialized branch of the labor law, because the distance of reality, even being dynamic and complex, makes it meaningless.

KEYWORDS Systemic interpretation, labor law, sustainability.

\section{Introdução}

É inequívoco que a sociedade está em constante transformação e que isso acarreta reflexos no âmbito do Direito, especialmente no ramo do Direito do Trabalho. Podese, inclusive, ir além e, transcendendo o Direito, perceber a evolução social a partir da arte ou da psicanálise: tudo está em constante transformação, em movimentos atrelados às flutuações sociais, em suas novas paletas de valores e de dinâmicas interativas.

A revolução tecnológica - que tantos avanços trouxe - eliminou determinados postos de trabalho, criando outros e exigindo dos trabalhadores uma especialização cada vez maior (e constante). Esses novos postos de trabalho assumem configurações completamente distintas do modelo tradicional (de trabalho) regrado pela Consolidação das Leis do Trabalho (CLT), em 1943. ${ }^{1}$ Aliado a tudo isso, constata-se que a globalização e a crise econômica ${ }^{2}$ apresentam desafios aos empreendedores para prosseguirem gerando postos de trabalho.

Defende-se no presente estudo que, exatamente dentro deste novo contexto fático, o Direito do Trabalho precisa ser normativa e dogmaticamente (re)pensado, como já ocorreu, por exemplo, no Direito das Famílias, nos Contratos ou no Processo Civil que, com isso, evoluíram e aproximaram-se dos fatos sociais. Ora, se tudo se transforma e se adapta aos ciclos dos seres humanos, por que não (re)construir o Direito do Trabalho a partir dos novos paradigmas do trabalho humano? Automação, transnacionalidade e inteligência artificial devem fazer parte da preocupação dos que constroem o Direito do Trabalho.

O Direito do Trabalho é composto por um conjunto de princípios, regras e instituições que possuem suas peculiaridades e, no Brasil, foram forjadas (em razão e) no contexto histórico-sociológico da $1^{\mathrm{a}}$ Revolução Industrial. ${ }^{3}$

Neste estudo, parte-se do pressuposto de que a Lei da Reforma Trabalhista (n. 13.467, de 2017), como constante da exposição de motivos de seu Projeto, é uma tentativa de «modernizar o Direito do Trabalho». Entretanto (igualmente em termos de

1. Sinale-se que pontuais alterações eventualmente operadas na CLT de 1943 não lograram atualizá-la a em de realinhá-la ao atual modelo de trabalho, quanto mais a prepara-la para o porvir.

2. Especialmente a iniciada nos Estados Unidos a partir de 2008, com reflexos mundiais.

3. Maiores digressões sobre as motivações para a codificação trabalhista no Brasil não cabem neste estudo, recomendando-se para tanto a leitura atenta da obra de Nascimento (2014). 
premissa), tem-se a impressão de que muito ainda lhe falta para o alcance de tal desiderato. Sinala-se que no âmbito do trabalho em plataformas digitais e do teletrabalho, v.g., gravita-se em um «terreno movediçoo», diante da insuficiência de regramento e de uma pulverização ideológica nas opiniões doutrinárias e decisões judiciárias o que, diante do perfil positivista do povo brasileiro, é fonte de insegurança jurídica.

O presente artigo se propõe a analisar a necessidade (e o método para) repensar o Direito do Trabalho a partir das novas configurações de (relações de) trabalho que a sociedade pós-moderna ${ }^{4}$ trouxe, para o que se o dividiu em três partes. Na primeira, aborda-se o progresso do mundo contemporâneo e a insuficiência da teoria jurídica da modernidade. Na segunda, demonstra-se a relação entre Direito e Sociedade, e a necessidade de (re)construção do Direito do Trabalho. E na terceira e última, a partir do pensamento sistêmico, busca-se demonstrar que a hipotrofia não atinge apenas ao Direito do Trabalho, mas também seus intérpretes, o que pode ser alterado imprimindo o racional pós-moderno na regulação e interpretação das relações de trabalho.

Propõe-se a ideia de que o Direito do Trabalho será sustentável na medida em que for aplicável, suficiente e eficaz à realidade do trabalho - moderno ou pós-moderno. O interprete instrumentalizará a sustentabilidade e, para tanto, deverá saber manejar métodos interpretativos tão complexos como os tempos ora vividos.

O estudo segue o método de abordagem hipotético-dedutivo, utiliza-se dos métodos de procedimento histórico, comparativo e fenomenológico e é conduzido pelo método de interpretação sistêmico. A pesquisa é eminentemente documental, baseando-se em referências bibliográficas brasileiras e estrangeiras, jurídicas ou não.

Espera-se, a partir da abordagem teórica realizada (incrementada pela expertise advocatícia de suas autoras), contribuir para um debate profundo sobre a necessária revisão de alguns paradigmas do Direito do Trabalho, como forma de garantir sua própria sustentabilidade.

\section{O mundo contemporâneo e o esgotamento dos postulados da Modernidade}

No cenário pós-moderno, a sociedade é regida por valores que lhe são peculiares. Se de um lado o mundo contemporâneo trouxe um progresso material impressionante, com descobertas e inovações tecnológicas sem igual; de outro, impôs à população a necessidade de adaptação a novas realidades.

Ao desenvolvimento e progresso das metrópoles industriais é possível vincular o enorme crescimento das classes médias urbanas e, com elas, um destaque deste século: a cultura de massa - produção cultural destinada aos grandes grupos de consumidores, simples e estereotipada, com objetivos claros e definidos.

4. Sobre o tema, vide Patterson (1996: 151 e ss.). 
A partir do final da primeira metade do Século XX, com o término da Segunda Guerra Mundial, a sociedade, mobilizada pela propaganda, pelo consumo e pela tecnociência aplicada à informação, passou a assumir novas feições. Abriu-se, então, espaço para a crítica de um ideal de racionalidade institucionalizado.

O desenvolvimento da ciência possibilitou o aumento do saber empírico, que foi colocado a serviço das forças produtivas. A moral, distanciando-se cada vez mais da religião, deu origem a uma nova ética do trabalho. Posteriormente, especialmente com o impulso da psicanálise, os mecanismos de repressão foram desvelados, invertendo-se a hierarquia tradicional entre a razão e as paixões com a valorização da espontaneidade e a supremacia do desejo em relação à racionalidade. A arte, igualmente distanciando-se da religião, tornou-se mais autônoma com a produção artística para o mercado.

Segundo Sérgio Rouanet (1998: 229-231), tais esferas atuando em espaços institucionais próprios - como universidades e centros de pesquisa, no caso das ciências; comunidade de fiéis, no caso da moral, e sistemas de produção, distribuição e consumo, no caso das artes - constituem-se elementos funcionais em relação à modernização social, o que não quer dizer que, vez por outra, não exista, entre elas e o próprio sistema social, elementos de contradição.

A pós-modernidade ${ }^{5}$ deslocou - uma da outra - as três grandes áreas da vida histórica: o conhecimento, a política e o desejo. O conhecimento se libertou de suas restrições éticas e amarras e partiu em busca do que antes era considerado «tabu», contando somente com a autoridade de seus poderes críticos e céticos. Com o nome de ciência, desligou-se do ético e do estético, perdendo, paulatinamente, contato com o valor. A investigação ética, desatrelada do aparelho eclesiástico, viu-se livre para levantar questões de justiça e de dignidade ${ }^{6}$ sob perspectivas muito mais abertas.

A arte, deixando de servir ao poder político e libertando-se de suas funções no interior da igreja, do tribunal e do Estado, passou a reger-se por suas próprias leis. O seu significado tornou-se, então, meramente suplementar, ligado ao lado afetivoinstintivo não-instrumental da psiquè, uma espécie de válvula de escape. Sua independência em relação ao ético e ao político, porém, se deu de forma paradoxal na medida em que aconteceu, em função de sua integração ao mercado, sua transformação em mercadoria. A estética, em contraposição, se propôs a reverter o processo de divisão das áreas da história, «estetizando» a verdade e a moral: propondo a arte como uma reconciliação ideal do sujeito com o objeto, do universal com o particular, da liberdade com a necessidade, da teoria com a prática, do indivíduo com a sociedade (Eagleton, 1993: 264-266).

Para Jean François Lyotard (1998), há em nossos dias rupturas e mudanças que ca-

5. Sobre a superada modernidade, escreveu Baudelaire (1996: 25).

6. Justiça e dignidade passariam a se constituir, então, nos novos padrões éticos. 
racterizam e constituem a pós-modernidade. Essas alterações fazem com que ocorra uma crise no conceito de racionalidade inaugurado pelo iluminismo. Para o autor, ciência e sociedade se constituem, em nossa contemporaneidade, numa complexa rede de jogos de linguagem, com seus próprios conteúdos e regras de legitimação, sem possibilidade de entendimento. A interpretação homogênea dos acontecimentos que, no início da era moderna se dava através das narrativas científicas ou filosóficas legitimadoras do saber, perdeu sua validade.

A conquista de novos conhecimentos no interior de 'jogos de linguagem' legitimadores torna-se restrita aos que podem mais e aos que dispõem de melhores condições financeiras, pois o saber está diretamente subordinado ao lucro. O saber, segundo Jean-François Lyotard (apud Goergen, 1996: 20), está sempre em busca da melhora de performance e do aumento de poder de seu usuário, com novas argumentações, novas regras e jogos de linguagem em que o consenso se torna inatingível. Para o autor, o conhecimento, hoje, está sempre se codificando e recodificando das mais diferentes maneiras, em função da transformação das condições técnicas e sociais da comunicação.?

Segundo Jean Chesneaux (1996: 35), a grande expansão do número de computadores conectados em redes exerce, em nossos dias, a exata função que as estradas de ferro um dia exerceram no sentido de anexar territórios ao mundo capitalista. As pressões financeiras que deslocam o espaço urbano são as mesmas que alteraram, anteriormente, o espaço rural e os bolsões de modernidade do terceiro mundo e são retransmissores do capitalismo mundial, como eram, no passado, as colônias tropicais das potências europeias. Mais do que nunca, produções e trocas servem para reproduzir o capital. A eficiência das empresas se define pela rentabilidade de seus investimentos e competitividade de seus produtos. A interpenetração do capital industrial e financeiro é a chave do poderio econômico. ${ }^{8}$

Pelo exposto, observa-se uma profunda modificação no âmbito da sociedade que possuía características próprias na chamada «modernidade». Segundo Hans Haferkamp (1992), a reflexão sobre o caráter da sociedade moderna pode ser mais bem entendida a partir da descrição de Max Weber sobre o racionalismo ocidental. Um dos pontos fundamentais do processo de racionalização do ocidente, segundo Max Weber, ${ }^{9}$ consiste na circunstância de não poder ser ela resumida como o advento

7. Massimo Canevacci (1988: 14-34), confirma o pensamento de Jean-François Lyotard: para ele há, realmente, em nossos dias, uma descrença generalizada na inelutabilidade do progresso e um crescente desconforto em relação à fixidez categórica do pensamento de tradição iluminista. Essa crise no conceito de racionalidade, instaurado pela filosofia das luzes, vem, sem dúvida, operando transformações no mundo da representação e do conhecimento. Ainda, segundo ele, as ideias nascem e se reproduzem diretamente das coisas, das mercadorias produzidas pela tecnología.

8. Sobre o tema, ver Forrester (1996), Virilio (1999) y Lèvy (1999).

9. Sobre o tema, ver Weber (1967: 19 e ss.). 
da técnica e da ciência, substituindo a fé pela razão, mas, sim, como uma tipologia de formas de ação ligada ao processo de desenvolvimento das diferentes religiões mundiais. ${ }^{10}$

A globalização cria relações de interdependência entre as distintas populações do planeta, reorganizando o tempo e a distância na vida social. Ela impõe uma nova estrutura no campo do poder. A forma estatal perde sua primazia ao subordinar-se a um soberano estatal privado »supra estatal», de caráter difuso. Através da globalização, deixa de haver fronteiras para os fluxos financeiros de bens e serviços (e esses fluxos são incessantes!). Estabelece-se também a globalização das comunicações. A globalização impõe uma nova estruturação do espaço e das distâncias, por uma parte, e do tempo, por outra. Ela se faz visível na grande superfície comercial.

A fase pós-industrial, por sua vez, coloca no mercado novos materiais químicos e tecnologia informática, permitindo inovações em todos os ramos da produção e novas técnicas de organização produtiva e empresarial, como as operações transnacionais, pelas quais o capital não conhece pátria. Com o avanço tecnológico, novos postos de trabalho surgem, eliminando outros, que se tornam obsoletos. Novas formas de trabalhar proliferam e as plataformas digitais e o teletrabalho, a exemplo do capital, desterritorializam ao trabalho.

Assim, pode-se dizer que a ideia principal da modernidade - fechamento e fragmentação do mundo - esgota-se na exata medida em que as mudanças se intensificam e geram um novo paradigma social, atingindo capitais, bens de consumo, seres humanos e instrumentos de controle social.

Segundo Alain Touraine:

Este esgotamento da ideia de modernidade é inevitável, já que ela se define não como uma nova ordem, mas como um movimento, uma destruição criadora, para retomar a definição de capitalismo de Schumpeter. O movimento atrai aqueles que durante muito tempo se fecharam na imobilidade; ele cansa, torna-se vertigem quando é incessante e não conduz senão à sua própria aceleração. Por ser a modernidade uma noção mais crítica que construtiva, ela requer uma crítica que seja por si mesma hipermoderna, o que protege contra as nostalgias que, sabemos, tornam facilmente uma aparência perigosa. O esgotamento da modernidade transforma-se com rapidez em sentimento angustiante do sem-sentido de uma ação que não aceita outros critérios que o da racionalidade instrumental. Horkheimer denunciou a degradação

10. «Weber also analyzed legal systems in terms of how legal decisions are made an the rationality of the procedures used of implementing the system... A rational system is one in which general rules are used to make decisions; an irrational system is one without a general system of rules. A formal system is one in which decisions are based on established rules of evidence and procedure, regardless of their fairness. A substantive system has no formal rules, and the circumstances of individual cases are taken into consideration alongside prevailing notions of justice» (Grana et al., 2002: 41). 
da «razão objetiva» na «razão subjetiva», isto é, de uma visão racionalista do mundo em uma ação puramente técnica pela qual a racionalidade é colocada ao serviço das necessidades, sejam elas a de um ditador ou as dos consumidores, que não são mais submetidos à razão e a seus princípios de regulamentação da ordem social assim como da ordem natural. Essa angústia leva a uma inversão de perspectiva. Bruscamente a modernidade é denominada «o eclipse da razão» por Horkheimer e Adorno e todos aqueles por eles influenciados, bem além da escola de Frankfurt (1995: 100-4).

As condições do crescimento econômico, da liberdade política e da felicidade individual não são mais análogas e interdependentes. A dissociação entre as estratégias econômicas e a construção de um tipo de sociedade, de cultura e de personalidade operou-se muito depressa e é ela que define a ideia de pós-modernidade.

Se a modernidade associou progresso e cultura, opondo culturas ou sociedades tradicionais e culturas e sociedades modernas, explicando todo fato social ou cultural pelo lugar que ocupa sobre o eixo tradição-modernidade, a pós-modernidade dissocia o que havia sido associado.

Gianni Vattimo (1994: 12) considera duas transformações como fundamentais para definir a pós-modernidade: i) o fim da dominação europeia sobre o conjunto do mundo; e ii) o desenvolvimento dos meios de comunicação que deram a palavra às culturas «locais» ou minoritárias. Desapareceu assim o universalismo que concedia uma importância central aos movimentos sociais que a Europa dos séculos XVIII e XIX supunha que lutavam a favor ou contra a razão e o progresso.

A sociedade industrial ampliou a complexidade socioeconômica e política. Segundo Juan Ramón Capella (1997: 239-240), uma nova cultura babélica assiste o confronto de tendências opostas: o impulso à barbarização de todas as relações sociais, que pode acabar em tiranias integrais e catástrofes sociais duradouras, e a enfraquecida tendência a uma posterior radicalização contra as desigualdades estruturais do processo de democratização. Willis Santiago Guerra Filho, por sua vez, ao tratar do assunto, refere que:

A pós-modernidade está no sentido de se resgatar uma periodicização, algo que o modernismo, por definição, impede - o atual, o presente, é sempre moderno. Na segunda metade do século em curso, estaríamos vivendo na pós-modernidade, devido ao modo radicalmente diverso como se organiza, econômica e politicamente, a sociedade egressa da modernidade, como uma correlata mudança no conjunto de crenças e pressuposições que formam a mentalidade dos que compõem, bem como pela natureza dos problemas que nela se apresentam. Tem-se a falência da ideia de que o conhecimento científico forneceria ao sujeito a verdade sobre os objetos que se colocavam diante dele. Há uma revalorização de formas pré-modernas, como a retórica, enquanto a doutrina do discurso razoável persuasivo e da hermenêutica, com seu intuito de compreender, mais do que explicar, como também o surgimento 
de novas formas de pensar, como a interdisciplinaridade, a postura científica crítica e as investigações psicoanalíticas (1998: 61).

O grande problema jurídico da atualidade é descobrir como pensar, organizar e operar o Direito no contexto da sociedade globalizada, especialmente neste período de transformações constantes e disruptivas. Examinar o Direito inserido na globalização implica relacioná-lo com a complexidade e com todos os processos de igualização, diferenciação e regulação social daí decorrentes. ${ }^{11}$

Em plena vigência da chamada sociedade globalizada, ainda é possível identificar o domínio das teorias jurídicas originadas na modernidade, presas à noção de Estado e de norma jurídica daquele período. ${ }^{12}$ Trata-se de teorias que têm como pressuposto teórico e epistemológico o normativismo, que vai difundir-se por todo o Ocidente como matriz teórica que representa o Direito na modernidade. ${ }^{13}$ Segundo Leonel Severo Rocha:

Dessa maneira, quando se ingressa numa nova forma de sociedade globalizada, que também poderia se denominar de transnacionalizada, ou pós-moderna, o problema é o fato de que qualquer perspectiva mais racionalista ligada ao normativismo e ao Estado se torna extremamente limitada. Não se pode, assim, continuar mantendo uma noção de racionalidade no Direito ao se insistir no ideal kelseniano (2003: 186).

Portanto, pode-se falar em uma crise do «Direito da Modernidade». Não se trata apenas de uma deficiência em sua estrutura tradicional, mas de uma crise da integração de seus pressupostos dogmáticos para funcionarem dentro da globalização. É preciso relacionar o Direito com a economia, a política e a sociologia, o que não é fácil. Conforme refere Leonel Severo Rocha (2003: 186): «Não basta apenas dizer-se que é preciso pensar-se o Direito juntamente com a política e a sociedade; quanto a isso, há um consenso. O problema está em atribuir um sentido pragmático a essa assertiva».

É preciso romper limites, tradições e zonas de conforto. No cenário trabalhista, os fatos políticos e socioeconômicos já não são os mesmos que deram ensejo à Consolidação das Leis do Trabalho (1943) ou mesmo à Constituição Federal (1988), entretanto, percebe-se a insistência em estabelecer uma hermenêutica com base nas matrizes jurídicas de então. A vertigem própria das mudanças no mundo dos fatos, inevitavelmente, atingirá o mundo jurídico e, então, normas relacionais de caráter provisório, poroso e negocial serão vistas como alternativa e necessidade. As velhas seguranças e as evidências estabelecidas por uma forma de pensamento de antanho produzem perplexidades e angústias para articular um programa de transformação

\footnotetext{
11. Neste sentido, ver Rocha (2003: 185).

12. Sobre o tema, ver Kelsen (1996).

13. Neste sentido, ver Severo Rocha (2003: 185).
} 
da sociedade que contemple o presente e o porvir. E é justamente diante destes dilemas que o Direito do Trabalho se encontra na atualidade.

\section{Direito e Sociedade: a necessidade de construção de um novo Direito do Trabalho como forma de sua sustentabilidade}

O Direito é fenômeno eminentemente social e possui sua existência atrelada à necessidade histórico-sociológica de condução e limitação dos comportamentos e das interações humanas. Para Rocha (2003: 188), entretanto, é preciso que se conceba a sociologia em ação e a sociedade em movimento e, daí, dada a intensa relação do fato trabalho com os extratos econômico e social, defende-se que é necessário pensar o Direito do Trabalho inserido nesta sociedade dinâmica, a partir de uma sociologia do trabalho arejada e conectada com a realidade.

É falsa a ideia de que o Direito possa ser neutro e livre de compromissos com a história e com o contexto político, cultural e social do qual brota. O Direito da atualidade é (ou deveria ser) fruto de movimentos e consensos sociais amplos, que ultrapassam fronteiras geográfico-territoriais e que são, naturalmente, temporários. Nicolai Hartmann, ao tratar do tema, refere que:

Nenhuma época pode ter por base pontos de vista que não sejam os seus. Naturalmente, estes não são absolutos, mas, sim, historicamente condicionados, e outras épocas terão razão se os abandonarem e substituírem pelos seus. Mas também eles estarão, por sua vez, condicionados (1983: 303).

Diante desta multifatoriedade e, para os fins deste estudo, observando o ramo específico do Direito do Trabalho, aponta-se a necessidade de sua análise em conjunto com todas as outras ciências que lhe orbitam, permeiam ou são por ele impactadas. Ao contrário do isolamento pregado pelos juristas da Idade Moderna, é mais do que hora de se deixar impregnar o Direito pelas questões que lhe são as verdadeiramente formadoras: os anseios da sociedade, a influência da economia, o avanço tecnológico, as repercussões da globalização, tudo isso deve estar contido naquilo que se entende por Direito do Trabalho.

Ocorre que, no sensível processo de alteração nos pesos desses valores (e quiçá até, em certo ponto, de seu contorno e conteúdo), que muitas vezes não é percebida por determinados operadores do Direito (Fincato, 2019), ${ }^{14}$ a resposta que os Poderes Legislativo e Judiciário dão à sociedade nem sempre é a esperada, causando, em alguns casos, frustração, perplexidade e insegurança. Por isso, a adequação da legislação vigente é fundamental. Segundo Augusto M. Morello::

14. Nesse sentido, já defendeu Fincato (2019).

15. «Por doquier se multiplican las denuncias de insatisfación por el servicio de la justicia. La impor- 
Onde quer que seja, multiplicam-se as denúncias de insatisfação pelo serviço da justiça. A importância do problema e a necessidade de atingir conquistas cumulativas indicam a conveniência de focar com a maior claridade possível um fenômeno que, claro está, não é simples, tem muitos rostos, complicações internas e fatores de pressão externa aos do serviço em si... Anunciam-se mudanças, inovações, uma modernização que vá de encontro a uma crise manifesta, palpável, que hoje domina a cena dessa 'administração' (Poder) fundamental para a paz social e a consolidação do Estado de Direito, com tudo o que traz para que não fique apenas na superfície, no formal, ao invés de estampar-se num Estado de Justiça (1998: 588).

É certo que algumas alterações legislativas já se operaram no âmbito do Direito do Trabalho, vindas, especialmente, no bojo da Reforma Trabalhista (Lei 13.467, de 2017) que foi proposta com a pretensão de alinhar o Direito do Trabalho à realidade social e às práticas internacionais (especialmente observando países que fizeram reformas e movimentaram-se sobre os mesmos eixos: negociação coletiva e flexibilidade contratual). ${ }^{16}$ De antemão, impõe referir que a Consolidação das Leis do Trabalho (CLT), até então, não havia sofrido alterações tão profundas e amplas.

As crises econômicas quebraram diversos paradigmas em países de índole «social» e fizeram ali descontruir-se o Direito do Trabalho tradicional, eminentemente protetivo e inibidor, para erigir-se um novo modelo, pautado na sustentabilidade, na liberdade contratual e na flexisegurança. É inequívoco que fenômenos como a automação, robotização e Inteligência Artificial têm influenciado os espaços produtivos em nível mundial, transformando os métodos de prestação de serviços e, sobretudo, reduzindo os postos de trabalho subordinado que ainda seguiam os moldes da Primeira Revolução Industrial.

A sustentabilidade, ${ }^{17}$ também é chamada de «direito ao futuro» e neste estudo é empregada como o direito-dever de preservar o Direito do Trabalho para as presentes e futuras gerações, obviamente que com as adaptações necessárias a permitir

tancia del problema y la necesidad de alcanzar logros acumulativos, señalan la conveniencia de centrar con la mayor claridad posible un fenómeno que, desde luego, no es simple, tiene muchos rostros, complicaciones internas y factores presionantes externos al del servicio en sí [...] Se anuncian cambios, innovaciones, una modernización que embista a una crisis manifiesta, palpable, que domina hoy la escena de esa 'administración' (Poder) fundamental para la paz social y la consolidación del Estado de Derecho, com todo lo que ello porta para que no se queden sólo en la superficie, lo formal, en lugar de plasmarse en un Estado de Justicia» (Morello, 1998: 588).

16. Assim, por exemplo, Espanha, Portugal, França e Itália, paradigmas comparativos possíveis ao Brasil em razão da proximidade de sistemas jurídicos e de legislações trabalhistas, já realizaram movimentos reformistas profundos e ainda seguem fazendo ajustes, numa ideia de movimento constante, doravante.

17. No Brasil, a sustentabilidade assenta-se na Constituição da República, especialmente nos arts. 3, 170, VI e 225. 
tal perenidade. Via sustentabilidade, se determina a promoção do desenvolvimento social, econômico, ambiental, ético e jurídico-político, com o objetivo de assegurar o bem-estar transgeracional. Nesse sentido, Juarez Freitas diz tratar-se

do princípio constitucional que determina, com eficácia direta e imediata, a responsabilidade do Estado e da sociedade pela concretização solidária do desenvolvimento material e imaterial, socialmente inclusivo, durável e equânime, ambientalmente limpo, inovador, ético, e eficiente, no intuito de assegurar, preferencialmente de modo preventivo e precavido, no presente e no futuro, o direito ao bem-estar (2016: 43).

No estudo feito por Freitas, ${ }^{18}$ destaca-se sua explicação sobre a dimensão sociojurídica da sustentabilidade (eis que multidimensional), na qual aponta que:

A sustentabilidade determina, com eficácia direta e imediata, independentemente de regulamentação, a tutela jurídica do direito ao futuro e, assim, apresenta-se como dever constitucional de proteger a liberdade de cada cidadão (titular de cidadania ambiental ou ecológica), nesse status, no processo de estipulação intersubjetiva do conteúdo intertemporal dos direitos e deveres fundamentais das gerações presentes e futuras, sempre que viável diretamente (Freitas, 2016: 43-44).

Como se pode intuir, neste estudo advoga-se a tese de que, a prosseguir desparceirando-se da realidade, o Direito do Trabalho já não se sustentará, sequer como instrumento para o alcance da justiça social, quanto mais como ramo autônomo da ciência jurídica, o que o levará à perda de sentido. Nesse linha, ao estudar o teletrabalho, Tybusch e Nunes (2017: 74), vinculam-no à sustentabilidade, alocando-o como propulsor de sua dimensão social, para o que apontam seus benefícios à vida de relação, à inclusão de determinados grupos e, até, à contenção (ou redução dos efeitos) de práticas criminosas. Veja-se:

Nesse cenário de transformações na sociedade global, a incorporação da modalidade de teletrabalho contribui para a sustentabilidade multidimensional, na medida em que favorece: o maior acesso das Pessoas Portadoras de Deficiência às oportu-

18. «Como se percebe, assim formulado, o desenvolvimento sustentável não é uma contradição em termos, tampouco se confunde com o delírio do crescimento econômico como fim em si. Estão reunidos os elementos indispensáveis para um conceito de sustentabilidade eficaz, a saber: (1) a natureza de princípio constitucional diretamente aplicável, (2) a eficácia (encontro de resultados justos, não mera aptidão para produzir efeitos jurídicos), (3) a eficiência (o uso de meios idôneos), (4) o ambiente limpo (descontaminado e saudável), (5) a probidade (inclusão explícita da dimensão ética), (6) a prevenção (dever de evitar danos certos), (7) a precaução (dever de evitar danos altamente prováveis), (8) a solidariedade intergeracional, com o reconhecimento dos direitos das gerações presentes e futuras, (9) a responsabilidade do Estado e da sociedade e (10) o bem-estar (acima das necessidades materiais)» (Freitas, 2016: 43-44). 
nidades de trabalho; à redução de preconceitos de várias origens (racial, religiosa, comportamental, etc.); aumento da segurança e redução dos atos de violência criminosa; contribui para a melhoria da saúde física e mental dos trabalhadores, bem como favorece ao fortalecimento das relações familiares e sociais; proporciona a revitalização dos centros comerciais dos bairros; contribui para a redução de custos pessoais dos trabalhadores.

Pois, o teletrabalho, embora exista desde os tempos do telégrafo ótico e seja realidade internacional ao menos desde a década de 70 do século passado (Fincato, Cracco Neto e Soria, 2013), somente foi inserido na Consolidação das Leis do Trabalho (Lei 5.452, de 1943) pela Reforma Trabalhista de 2017, não sem críticas.

A Reforma Trabalhista brasileira foi polêmica desde seu princípio, gerando debates sociais infindáveis e muita disputa política. Como resultado disso, três dias após sua entrada em vigor, foi editada a Medida Provisória n 808, de 2017 que teve por objetivo «alterá-la» e, com sua perda de vigência, surgiu a Portaria no 349 , de 2018 , do Ministério do Trabalho, pela qual se buscou «regulamentar» a Reforma Trabalhista. Não suficiente, em matéria processual, opera-se atualmente sob a regência de uma Instrução Normativa do Tribunal Superior do Trabalho e, a piorar, questionado sobre a (in)constitucionalidade de diversos dispositivos, o Supremo Tribunal Federal (STF) segue silente em grande parte dos mesmos. O quadro, como se percebe da própria narrativa, é confuso e gera insegurança jurídica extrema.

A exposição de motivos do Projeto de Lei (PL) n. 6787, de 2016 apontava o desiderato de «modernização» da reforma trabalhista brasileira. Mais que isso, tal texto revelava uma espécie de cansaço, uma falta de paciência com a ineficiência sindical, com o engessamento do contrato de trabalho subordinado, com o ativismo judicial, enfim, descrevia uma desorientação ${ }^{19}$ do ordenamento trabalhista brasileiro, defasado e desvinculado da realidade. ${ }^{20}$

Entretanto, entende-se que modernizar uma legislação implica alinhá-la aos fatos sociais que passará a reger, além de torná-la acessível aos seus destinatários, ou seja, escorreita de dúvidas interpretativas. No tocante ao alinhamento ao fato social

19. O termo desorientação pode ser empregado em diversos contextos. No âmbito da crise, segundo Masi: «Nessuno potrebbe restare impassibile di fronte a um cambiamento di tale portata. La sensazione piú diffusa è il disorientamento [...] In sintesi, il disorientamento si traduce in paure che la maggioranza della popolazione non riesce a esorcizzare: paura della guerra, della epidemia, degli immigrati, della sovrappopolazione, dell'inquinamento, della violenza, della promiscuità, del multiculturalismo, dei crolli in borsa, della solitudine, della noia, della norte, dell'aldilà» (Masi, 2015).

20. «A inteligência artificial, por exemplo, tem sido comparada à eletricidade. É uma tecnologia de propósito geral que, ao longo do tempo, chegará a quase todos os aspectos da vida. Isso deverá trazer mudanças significativas no trabalho e na sociedade. A corrida na direção ao futuro encontrou o Brasil no contrapé - ocupado com suas crises e interminavelmente conflagrado por disputas sobre narrativas que traduzam um projeto nacional» (Gaetani e Almeida, 2019). 
trabalho, afora a franciscana referência ao teletrabalho, ${ }^{21}$ nada mais se observa em termos de intenção de regência, atual e prospectiva, sobre o trabalho tecnológico ou os chamados empregos verdes, ${ }^{22}$ por exemplo. Em acréscimo, observa-se que a legislação segue majoritariamente voltada ao trabalho subordinado, a tempo contínuo e presencial - cada dia mais escasso-e ignora o grande impacto das tecnologias de informação e comunicação, que permitem a fluidificação da relação de trabalho. ${ }^{23}$

Em termos qualitativos, a Reforma Trabalhista afeta as relações individuais e coletivas de trabalho, o direito processual do trabalho e, ainda, condiciona as relações institucionais especialmente pretendendo conter o excesso de litigiosidade. Quantitativamente, dos dezenove artigos do originário PL n. 6.787, de 2016, passou-se a uma centena com o PLC n. 38, de $2017,{ }^{24}$ aproximadamente noventa deles (sem considerar os incisos, parágrafos e alíneas acrescidos) alterariam a Consolidação das Leis do Trabalho (CLT) e quatro afetariam a Lei do Trabalho Temporário (6.019, de 1974). O projeto fazia menções, ainda, às leis 8.036, de 1990 (Lei do Fundo de Garantia do Tempo de Serviço - FGTS) e 8.212, de 1991 (Lei do Custeio da Seguridade Social), sem grande impacto às mesmas, no entanto.

Em grandes eixos, pode-se dizer que a Reforma Trabalhista brasileira atuou sobre:

- As relações individuais: reconhecendo a autonomia individual da vontade em algumas hipóteses concretamente delimitadas (distratos em relações de «hi-

21. Vide artigos 62, III e 75-A e seguintes da CLT.

22. «Os empregos verdes trazem a promessa de que a humanidade saberá enfrentar os dois desafios definitivos do século XXI: evitar as mudanças climáticas perigosas e potencialmente inadministráveis e proteger o meio ambiente natural, que sustenta a vida no planeta; e garantir trabalho decente e, portanto, uma perspectiva de bem-estar e dignidade para todos em face do rápido crescimento demográfico mundial e do cenário atual de mais de um bilhão de pessoas excluídas do desenvolvimento econômico e social». Sobre o tema, ver: Organização Internacional Do Trabalho. Empregos verdes: Trabalho decente em um mundo sustentável e com baixas emissões de carbono. Disponível em http://bit.ly/2wu5onk (Cecato e Oliveira, 2016: 210-211).

23. Já se afirmou em estudo anterior: «O tempo, na atualidade, corre com outra velocidade (obviamente mais acelerado). E se já é clássica a ideia de que após a ocorrência do fato há sua valoração social e só então o surgimento da norma, gerando sensação de descompasso e, porque não, certo desamparo, em dias atuais o intervalo entre o fato e a norma aumenta, eis que a valoração do fato é demasiadamente complexa e controversa. Sabe-se, portanto, que o tempo da lei é outro e, diante desta premissa, as negociações coletivas [...] revelam-se espaços democráticos, dinâmicos e flexíveis para a regulamentação essencial de que se ressente o meio laboral de determinadas sociedades ante o avanço das tecnologias» (Fincato, 2014: 16).

24. Sem dúvidas, tratou-se de uma alteração de relevo, não sem parâmetros para o Brasil, que já realizou atualizações, legislativas de fôlego em sua história quando, por exemplo, em 2002, promulgou o novo Código Civil (substituindo grande parte do texto de 1916) ou em 2015 editou o novo Código de Processo Civil (substituindo muitos dos dispositivos do diploma de 1973), sempre precedendo tais momentos por grandes debates e períodos de apreensão. 
persuficientes», composição de jornadas, etc); criando um modelo regulatório da terceirização; ampliando o tempo e o uso dos contratos temporários (com geração de empregos).

- As relações coletivas: garantindo a eficácia dos acordos e convenções coletivas em face do texto legal (casos enunciados, limitações legais); estimulando a reforma sindical, uma vez que trouxe a eliminação da obrigatoriedade do imposto sindical (registre-se que a reforma não ultrapassa as garantias mínimas do artigo 7 da Constituição Federal, mesmo ao admitir a prevalência do negociado sobre o legislado).

- O Processo do Trabalho: buscando viabilizar a dinamização da tramitação processual, a redução da litigiosidade e dos traços excessivamente protetivos na operação judicial, além de controlar o chamado «ativismo judicial».

Todavia - em observação sistêmica e a partir de uma sociologia dinâmica - afirma-se que os avanços trazidos pela Reforma Trabalhista ainda foram muito tímidos ${ }^{25}$ $(\text { Fincato, 2017) })^{26}$ e, por isto, entende-se que os movimentos reformistas tendem a prosseguir. Pode-se afirmar, por exemplo, que o «novo trabalho» não foi contemplado, eis que ausentes previsões sobre o trabalho em plataformas digitais, o direito à desconexão ou à proteção de dados pessoais.

Entende-se, ainda, que a Reforma fracassou na tentativa de «simplificação» da regulamentação das relações de trabalho. Se o cenário antes era antiquado e confuso (dado o emaranhado de leis, súmulas e orientações jurisprudenciais a manejar em cada contrato), agora é parcialmente antiquado, ainda mais confuso e tremendamente inseguro (pois poucos arriscam dizer o que efetivamente é legal, constitucional ou até mesmo «convencional» na Reforma Trabalhista). Sem dúvidas, a operação juslaboral contemporânea exige do intérprete muito mais que a dicção da literalidade da lei, pois esta pode não adequar-se à realidade fática a ser regrada. Quiçá a saída seja, realmente, a operação interpretativa complexa e variável: ora sistemática, ora sistêmica?

\section{Adequação do Direito do Trabalho à sociedade (realidade): uma leitura sistêmica}

Todo o até aqui exposto deixa deduzir que o manejo do método sistêmico é necessário ao intérprete da atualidade. Dada a tradição e algum atrelamento a zonas de conforto, no Direito do Trabalho ainda se utiliza, prioritária e maciçamente, do método

25. Sendo esta a opinião das autoras, em que pese posições em contrário, visualizáveis, por exemplo, nos chamados «Enunciados da ANAMATRA», disponíveis em http://bit.ly/2WG6OIt.

26. Neste sentido, Fincato (2017). 
sistemático na interpretação de fatos e resolução de casos, o que é o cerne da crítica exposta neste estudo.

O método (ou pensamento) sistemático permite que elementos sejam reunidos num mesmo conjunto, seguindo uma mesma ordem organizativa (Mezzaroba e Monteiro, 2008: 76) e, no campo jurídico, pode-se dizer que está voltado para o estabelecimento de uma ordem interna que é hierarquizada e autossuficiente (Gomes, 2015) e que não se relaciona com o meio exterior.

Por sua vez, o método (ou pensamento) sistêmico ${ }^{27}$ ultrapassa tais objetivos, uma vez que o conjunto dos elementos sistêmicos estará disposto em relação de interação também com o ambiente (contexto), ou seja, com elementos de fora do sistema em observação focal, o que certamente quebrará com os critérios habituais de hierarquia e autossuficiência, trazendo certo desconforto ao intérprete forjado noutra época, especialmente porque não será possível analisar apenas o sistema e sua relação com o contexto (o que já é especialmente complexo) pois há inúmeros outros sistemas que interagem entre si e com o contexto, em constante dinâmica ${ }^{28}$, e que devem ser observados e analisados concomitantemente (Fincato e Gillet, 2018).

O pensamento sistêmico, paradigma científico cujos pressupostos são a complexidade, a instabilidade e a intersubjetividade (Gomes, 2015), permite a consideração de múltiplos vieses, variáveis, partes e relações de fatos e problemas e, com isto, passa a ser possível admitir respostas combinadas e precárias (provisórias, temporárias, não estáveis ou permanentes) às indagações. ${ }^{29}$

27. Sobre o tema, ver Parsons e Shils (1990: 39-46); Bell (1990: 319-329); Lyortard (1998: 330-341); Habermas (1990: 342-354); Huyssen (1990); Eyerman (1992: 37-54); Tiryakian (1992: 78-96); Haferkamp (1992: 97-121); Calhoun (1992: 205-236); Eisenstadt (1992: 412-430).

28. «Al analizar las interrelaciones entre los cuatro subsistemas de acción - y entre estos subsistemas y los ambientes de la acción - es esencial tener en cuenta el fenómeno de la interpenetración. Es posible que el caso mejor conocido de interpenetración sea la interiorización de objetos sociales y normas culturales en la personalidad del individuo. [...] Los procesos de intercambio entre los sistemas pueden tener lugar en virtud de la existencia de zonas de interpenetración [...] Para poder 'comunicar-se' simbólicamente, los individuos deben observar códigos comunes, organizados culturalmente como los del lenguaje, que se integran en sistemas de su interacción social. ... Así, consideramos que los sistemas sociales son 'abiertos' y participan en un intercambio continuo de insumos y productos con sus ambientes» (Parsons, 1974: 15-16).

29. Segundo Niklas Luhmann e Raffaele de Gerorgi, «la sociedad moderna no está constituida por individuos y que no puede ya ser descrita como si estuviera constituida por individuos, sino que debe atribuir a los individuos, en cuanto existencias mentales y corporales, una posición externa. Esta también es una consecuencia necesaria de la diferenciación funcional; y, en efecto, esta forma de la diferenciación excluye que los individuos concretos se distribuyan entre los sistemas individuales de funciones, por ejemplo, entre las familias, las casas, los pueblos y las ciudades o los estratos sociales. Ahora cada individuo debe poder participar en todos los sistemas de funciones; como consecuencia, es necesario volver a pensar el nuevo significado que adquiere el principio da inclusión social, y es necesario ade- 


\section{Gomes (2015) pontua que:}

Conquanto os pressupostos da objetividade, simplicidade e estabilidade continuem vigentes nos pensamentos científico e comum da atualidade, é preciso destacar que, especialmente a partir da segunda metade do século XX, um grupo de pensadores de vários campos do conhecimento começou a questionar os paradigmas tradicionais de ciência, desencadeando o início de uma virada epistemológica e o surgimento de novos pressupostos para a racionalidade científica (Gomes, 2015: 83).

Daí inicia-se um processo de reconhecimento de que o ideal de simplificação (racional da Modernidade), não corresponde à realidade dos fenômenos da contemporaneidade, extremamente complexa, repleta de paradoxos e contradições (racional da Pós-modernidade). Isso implica um retorno de procedimento: da extração dos objetos de seu contexto (análise pura e estática, típica da Modernidade), passa-se à sua inclusão e/ou manutenção no contexto (análise impregnada e dinâmica, típica da Pós-Modernidade). O ideal de estabilidade, ordenação e controlabilidade dos fenômenos deixa de ser perseguido, dada a compreensão de que o mundo está em constante transformação, motivo do qual decorrem instabilidade, imprevisibilidade e desordem (Vasconcellos, 2002: 118-129).

Nesse cenário, também se passa a admitir que o conhecimento acerca de um objeto depende, em importante parte, da relação estabelecida com seu observador (Vasconcellos, 2002: 243), o que leva à superação da busca «da verdade» ou do imperativo de condução dos processos científicos à luz da «objetividade»: existem várias verdades e, deve-se reiterar, nas ciências humanas e sociais, a evolução científica é uma construção social, constante e mutante.

O método ou pensamento sistêmico, ${ }^{30}$ que se aponta como ferramenta imprescindível ao legislador, pesquisador ou intérprete juslaboral da atualidade, possui gênese

más encontrar reglas nuevas para el uso de nuevos conceptos de valor, como libertad e igualdad. ¿Qué les sucede después a los mismos individuos? Y éste es precisamente el tema sobre el cual sigue siendo necesario llegar a un acuerdo con la ayuda de la nueva distinción entre individuo y sociedad. Esta distinción registra el hecho de que entre el final del siglo XVIII y el inicio del siglo XIX el individuo alcanzó una posición de un nuevo tipo, es decir, la posición de valor supremo (y cuando se quiere mencionar precisamente este hecho, al individuo se le llama sujeto). A su vez, esta colocación del individuo en una posición que transciende las valoraciones que circulan en la sociedad y que se presenta como su premisa, está condicionada por el hecho de que el cambio radical de las formas de la diferenciación social revoluciona la semántica tradicional de la inclusión y obliga a poner al individuo como elemento externo a la sociedad» (Luhmann e Georgi, 1993: 421).

30. «Le système, selon von Bertalanffy, 'est un ensemble d'unités en interrelations mutuelles (A system is a set of unities with relationship among them). Les qualités émergentes résultent des interrelations mutuelles entre éléments. La théorie des systèmes a eu le mérite de montrer la généralité du système: des atomes aux étoiles, en passant par les êtres vivants et la société, tout est système» (Fortin, 2000: 32). 
transdisciplinar (Gomes, 2015) e foi desenvolvido pelo sociólogo Niklas Luhmann, ${ }^{31}$ que ajustou os conceitos próprios dos sistemas biológicos à realidade dos fenômenos sociais, distinguindo-os a partir de seus elementos constitutivos e reprodutivos, respectivamente, vida e comunicação (Luhmann, 2011: 213).

É destacada a atuação dos sociólogos na tentativa de decodificação das relações sociais da pós-modernidade, neste sentido, além de Luhmann, é intensa a atuação de Zygmunt Bauman, Edgar Morin e Domenico de Masi, cujas obras são de leitura obrigatória aos juslaboralistas que pretendam acompanhar as transformações do mundo do trabalho.

As lições dos sociológos sistêmicos são deveras importantes ao momento atual do Direito do Trabalho. É a partir de Luhmann (Gomes, 2015), por exemplo, que se percebe que o contexto não pode ditar ao sistema nele contido sua forma ou funcionamento e que, da mesma maneira, o sistema não estará imune às «irritações» de seu contexto. Destarte, o arcabouço normativo não pode ignorar as transformações sociais, tampouco pretender regê-las sob formato e critérios valorativos fixos, prédeterminados e distantes de sua realidade. De outro lado, o contexto fático não estará imune às regulações ditadas pelo contexto, sofrendo, ambos, recíprocos e constantes «amoldamentos».

As transformações no cenário trabalhista, especialmente impulsionadas pelos momentos de crise econômica e pelo avanço tecnológico, dão suporte aos marcos histórico-evolutivos fixados pelas (r)evoluções industriais. Da Primeira à Terceira Revoluções, em termos tecnológicos, há evolução nos processos e equipamentos. $\mathrm{Na}$ Quarta Revolução, pode-se dizer que há real revolução, pois seu contexto e dinâmica são absolutamente originais, não evoluem de nada e não aperfeiçoam qualquer coisa. Tudo é novo, inédito e, de certa forma, inesperado.

A proposta ao Direito do Trabalho, para alinhar-se à Pós-Modernidade e servir ao porvir é, portanto, revolucionária e disruptiva. Sem desprezar a importância e valor evolutivo do conjunto até aqui construído, romper com vícios legislativos e interpretativos comodistas e tradicionais parece ser a melhor forma de efetivamente aplicar o Direito ao Trabalho.

31. «Niklas Luhmann sees complexity and contingency in less alarmist terms. The distinction complexity/simplicity no longer holds, he claims, because in the modern world (including modern science), the search for an underlying simplicity has become futile... Complexity, then, becomes not a property of a system but a mode of observation - indeed, the mode of observation... Complexity guarantees contingency, which is to say, creates meaning - the difference between potentiality and actuality. We can observe the selections that are made; others can observe ours and we can observe theirs; we can even use schemas like truth/opinion, correctness/error, or affirmation/critique to observe others' schemas» (Rasch, 2000: 33-34). 


\section{Conclusão}

A inquietação científica para este trabalho surgiu da observação da dificuldade de grande parte dos operadores jurídicos em entender dispositivos (legais ou negociados) de caráter flexisseguro ou a novel regulamentação de novos arranjos produtivos (como os contratos de terceirização ou de trabalho intermitente). Verifica-se em seus discursos uma acusação de «desconformidade» ao sistema, identificando-se em suas condutas a desacomodação referida por Domenico de Masi.

É importante registrar que a abordagem jurídica sistemática possui um espaço histórico, estrutural e funcionalista importante no contexto jurídico brasileiro e que, como em outros países, durante muito tempo o Direito foi influenciado (senão conduzido) pela moral e/ou religião.

A ciência jurídica não pode ficar alheia aos influxos das transformações que já atingem as ciências em geral. Mas se reconhece que determinadas áreas do Direito, quiçá por não estarem tão afetas a interferências ideológico-partidárias, sensibilizaram-se e movimentaram-se mais rápido em suas adequações jurídicas (como no Direito das Famílias, por exemplo). Atentaram-se para a necessidade de espelhamento dos fatos no Direito e vice-versa. Quando o Direito não espelha mais os fatos (ou quando os fatos não se enxergam mais no Direito vigente) surge a insegurança jurídica e, pior de todos os males, a injustiça.

Adaptar-se, de forma constante e, por vezes, com saltos disruptivos, é empregar o pensamento sistêmico, o que exige do operador jurídico (legislador ou intérprete) a resiliência fundamental para viver em contextos mutantes e instáveis e, ainda, a técnica necessária a bem atuar. Surge, como habilidade exigida aos profissionais do Direito, a necessidade de manuseio consciente e sereno da Teoria dos Sistemas e do Método Sistêmico. Isto implica, na ação jurídica, em transitar por outras áreas do saber, admitindo ainda que a amostra do microscópio estará em mutação, movimento e interação, o tempo todo.

Pelo exposto neste estudo e com foco nas relações de trabalho e no Direito do Trabalho, acredita-se no abrandamento gradual dos pressupostos operativos do paradigma sistemático, fazendo-se substituir pelo pensamento sistêmico. A aproximação do Direito do Trabalho às essências da economia, política, sociologia e ética levam à superação dos paradigmas da estabilidade e simplicidade.

O Direito do Trabalho Pós-Moderno deve atender, com eficiência, à complexidade dos fatos por ele regidos. Deve ser suficientemente maleável e coerentemente provisório, para amoldar-se às transformações valorativas e relacionais do meio. Deve dialogar com outros sistemas sociais e abrir-se à transdisciplinariedade.

Nesse diapasão, não é fora de lógica advogar a ideia de que, um dia, não será mais possível regular todos os fatos de uma relação trabalhista (coletiva ou individual) pela lei. Daí apontar-se para a negociação coletiva e para a emancipação do trabalhador 
(com a valorização de sua autonomia) como mecanismos de manutenção da eficácia do Direito do Trabalho. Dada a realidade Pós-Moderna, há sentido em garantir a prevalência sobre o legislado a tais normas de caráter individual, precário e teleológico. Imagina-se que o reflexo disso na prática jurídica será a busca de um Direito cada vez mais consensual, em todos os seus processos de elaboração e interpretação/aplicação.

Passado certo tempo do vigor da Reforma Brasileira, embora seja precipitado a esta atribuir qualquer efeito econômico ou social, já se percebe a redução de ajuizamentos trabalhistas ${ }^{32} \mathrm{e}$, ainda, alguns números indicando aumento na geração de empregos $^{33}$. Com isto assinala-se que a reforma atingiu alguns de seus desejos: reduziu a utilização aventureira da Justiça Especializada do Trabalho e fomentou a regularização do trabalho, especialmente a partir da admissão de novas formas de ocupação subordinada (contrato intermitente, p.ex.) e, ainda, de fórmulas de retribuição do trabalho menos onerosas ao empregador (desoneração da folha com a nova redação do art. $457 \$ 2^{\circ}$ da CLT).

Entretanto, enquanto tentativa de modernização do Direito do Trabalho, a Reforma Trabalhista falhou. Não contemplou o novo trabalho, não filtrou a legislação de seus cacoetes e institutos antiquados («juntas de conciliação e julgamento», «teatro de revista», entre outros) e, pior, não contribuiu para a pacificação social.

Como perspectiva aos próximos anos, acredita-se que as operações jurídicas serão adaptadas aos perfis dos casos que se apresentem, quer ao legislador, quer ao magistrado ou advogado. Destarte, o método sistemático (que poderá, até mesmo, ser desempenhado pela inteligência artificial ${ }^{34}$ ) seguirá sendo empregado aos casos em geral (repetitivos, comuns) e o método sistêmico, que depende da criatividade humana, aos hard cases.

Em suma: na Pós-Modernidade, admitir operar com relações e ordenamentos líquidos será o primeiro passo para, paradoxalmente, alcançar a concretização da Justiça e, no plano da regulamentação das relações trabalhistas, esta será sua condição de sustentabilidade.

\section{Referencias}

Baudelaire, Charles (1996). Sobre a modernidade. São Paulo: Paz e Terra.

BELL, Daniel (1990). «Modernism, postmodernism and the decline of moral order». In: Alexander, Jeffrey et al. Culture and society: contemporary debates. New York: Cambridge University Press.

32. Mais sobre o tema, ver em http://bit.ly/3oZSKZG.

33. Sobre a informação, ver por exemplo http://bit.ly/3oZAKP3.

34. Neste sentido, observar as funcionalidades crescentes do chamado sistema Bem-te-vi, do Tribunal Superior do Trabalho: http://bit.ly/2WA207D. 
CalHoun, Craig (1992). "The infrastucture of modernity: indirect social relationships, information technology, and social integration". In Haferkamp, Hans and Neil J. Smelser (ed.), Social change and modernity. Berkeley, Los Angeles, Oxford: University of California Press.

Canaris, Claus-Wilhelm (1996). Pensamento sistemático e conceito de sistema na ciência do direito, 2. ${ }^{a}$ ed. Lisboa: Fundação Calouste Gulbenkian.

CanevacCI, Massimo (1988). Antropologia da Comunicação. São Paulo: Brasiliense.

CAPELla, Juan Ramon (1997). Fruta prohibida: Una aproximación histórico-teorética al estudio del Derecho y del Estado. Madrid: Trotta.

Cecato, Maria Aurea Baroni e Flavia de Paiva Medeiros de Oliveira (2016). «Trabalho decente e emprego verde: Uma análise à luz do caráter pluridimensional da sustentabilidade». Revista de Direito e Sustentabilidade; 2 (2).

Chesneaux, Jean (1996). Modernidade-Mundo, 2. ${ }^{a}$ ed. Traduzido por João da Cruz. Petrópolis: Vozes.

Eagleton, Terry (1993). A ideologia da Estética. Traduzido por Mauro Sá Rego da Costa. Rio de Janeiro: Jorge Zahar.

EisenstAdT, S.N. (1992). «A reappraisal of Theories os social change and modernization». In: Haferkamp, Hans and Neil J. Smelser (ed.). Social change and modernity. Berkeley; Los Angeles: Oxford University of California Press.

Eyerman, Ron (1992). «Modernity and Social Movements». In Haferkamp, Hans and Neil J. Smelser (ed.), Social change and modernity. Berkeley, Los Angeles: Oxford University of California Press.

Fincato, D.P. (2014). «Trabalho e Tecnologia: reflexões». In Fincato, D.P; C. Guimares e M. Matte. Direito e Tecnologia: reflexões sociojurídicas. Porto Alegre: do Advogado.

Fincato, D.P. e S.A. Gillet (2018). Pesquisa Jurídica sem Mistérios: do Projeto de Pesquisa à Banca, 3. ${ }^{\text {a }}$ ed. Porto Alegre: FI.

Fincato, Denise (2019). «Miopia e Reforma Trabalhista». O Estadão, 17 jan. 2019. Disponível em http://bit.ly/2IdL6IV.

Fincato, Denise (2017). «Novo Trabalho, Novo Direito». O Estadão, 10 nov. 2017. Disponível em http://bit.ly/2MlfXCk.

Fincato, D.P; H. B. Cracco Neto e J. S. Soria (2013). «De Chappe a Nilles: a evolução da tecnologia no trabalho e a invenção do teletrabalho - uma revisão necessária». In: Strapazzon, C.L.; R. Goldschimidt, e R. Tramontina (Org.). Teoria Geral e Mecanismos de Efetividade no Brasil e na Espanha: Tomo I (Série Direitos Sociais Fundamentais). Joaçaba: UNOESC, v. 1: 109-121.

Forrester, Viviane (1996). O Horror Econômico. Traduzido por Álvaro Lorencini. São Paulo: UNESP.

ForTin, Robin (2000). Comprendre la Complexité: Introduction à la Méthode d'Edgar Morin. Canadá: L'harmattan. 
Freitas, Juarez (2016). Sustentabilidade: direito ao futuro. Belo Horizonte: Fórum.

Gaetani, Francisco e Virgílio Almeida (2019). «O avanço digital e a natureza do trabalho em mutação». Valor Econômico online. 07 fev. 2019. Disponível em: http:// bit.ly/2XsxbyZ.

Goergen, P. (1996). «A crítica da modernidade e a educação». Revista Pro-Posições, 7 (2).

Gomes, Ana Carolina Oliveira (2015). «Do pensamento sistemático ao pensamento sistêmico e seus reflexos na ciência do direito». Revista de Teorias do Direito e Realismo Jurídico, 1 (2): 80-102.

Grana, Sheryl J. et al. (2002). The social context of law. 2. ${ }^{\mathrm{a}}$ ed. Upper Saddle River, New Jersey: Prentice Hall.

Guerra Filho, Willis Santiago (1998). «Pós-modernismo, pós-positivismo e o Direito como filosofia». In Oliveira Jr., José Alcebiades. O Poder das Metáforas: homenagem aos 35 anos de docência de Luís Alberto Warat. Porto Alegre: Advogado.

Habermas, Jürgen (1990). «Modernity versus postmodernity». In: Alexander, Jeffrey et al. Culture and society-contemporary debates. New York: Cambridge University Press.

Haferkamp, Hans (1992). «Modernity and Ascription». In Smelser, Neil J. Social change and modernity. Berkeley. Los Angeles: Oxford University of California Press.

Hartmann, Nicolai (1983). A filosofia do idealismo alemão. Lisboa: Fundação Calouste Gulbenkian.

Huyssen, Andreas (1990). «Mapping the postmodern». In: Culture and society-contemporary debates. New York: Cambridge University press.

Kelsen, Hans (1996). Teoria Pura do Direito, 5. ${ }^{a}$ ed. São Paulo: Martins Fontes.

LÉvy, Pierre (1999). Cibercultura. Traduzido por Carlos Irineu da Costa. Rio de Janeiro: Editora 34.

Luhmann, Niklas (2011). Introdução à Teoria dos Sistemas, 3. ${ }^{\mathrm{a}}$ ed. Petrópolis-RJ: Vozes.

Luhmann, Niklas y Raffaele de Georgi (1993). Teoría de la sociedad. Guadalajara (México).

Lyotard, Jean François (1998). A condição pós-moderna. Traduzido por José Bragança de Miranda. Lisboa: Gradiva.

MAsi, Domenico de (2015). TAG: Le parole del tempo. Milano: Compos 90.

Mezzaroba, Orides e Cláudia Servilla Monteiro (2008). Manual de metodologia da pesquisa no direito, 4 ed. São Paulo: Saraiva.

Morello, Augusto M. (1998). Estudios de Derecho Procesal I. Buenos Aires: AbeledoPerrot S.A.

Nascimento, Amauri Mascaro (2014). Iniciação ao Direito do Trabalho. 39. ${ }^{a}$ ed. São Paulo: LTr.

Parsons, Talcott (1974) El Sistema de las Sociedades Modernas. Traduzido por Agustin Contin. México: Editorial Trillas. 
Parsons, Talcott and Edward Shils (1990). «Values and social systems». In: Alexander, Jeffrey C. et al. Culture and Society: Contemporary Debates. Cambridge University Press.

Patterson, Dennis (1996). Law \& Truth. New York: Oxford University Press.

Rasch, William (200o). Modernity-The Paradoxes of Differentiation. Stanford: Stanford University Press.

Rocha, Leonel Severo (2003). Epistemologia Jurídica. São Leopoldo: Edunisinos.

Rouanet, Sérgio (1998). As razões do Iluminismo. São Paulo: Companhia das Letras.

Түвиsch, Jerônimo Siqueira e Denise Silva Nunes (2017) «O Teletrabalho sob o enfoque da sustentabilidade multidimensional». In: Colnago, Lorena de Mello Rezende; José Eduardo de Resende Chaves Junior e Manuel Martín Pino Estrada (Coord.). Teletrabalho. São Paulo: LTr.

Tiryakian, Edward A. (1992). Dialectics of Modernity: reenchantment and Dedifferentiation as Counterprocesses. In: HAFERKAMP, Hans and Neil J. Smelser (ed.), Social change and modernity. Berkeley, Los Angeles: Oxford University of California Press.

Touraine, Alain (1995). Crítica da modernidade. Traduzido por Elia Ferreira Edel. 3. ${ }^{\mathrm{a}}$ ed. Rio de Janeiro: Vozes.

VAsconcellos, Maria José Esteves (2002). Pensamento sistêmico: o novo paradigma da ciência. Campinas: Papirus.

Vattimo, Gianni (1994). En torno a la posmodernidad. Santafé de Bogotá: Anthropos. Virilio, Paul. (1999). A Bomba Informática. Traduzido por Luciano V. Machado. São Paulo: Estação Liberdade.

Weber, Max (1967). A ética protestante e o espírito do capitalismo. Traduzido por M. Irene de Q. F. Szmrecsânyi e Tamás J. M. K. Szmrecsányi. São Paulo: Pioneiras Sociais.

\section{Sobre os autores}

Denise Pires Fincato es Pós-Doutora em Direito do Trabalho pela Universidad Complutense de Madrid. Professora Titular e Pesquisadora no Programa de Pós-Graduação em Direito da Pontifícia Universidade Católica do Rio Grande do Sul. Advogada e Consultora Trabalhista, sócia de Souto, Correa, Cesa, Lummertz e Amaral. E-mail:dpfincato1@gmail.com.

Jaqueline Mielke Silva es Doutora e Mestre em Direito Público pela Universidade do Vale do Rio dos Sinos. Especialista em Direito Processual Civil pela Pontifícia Universidade Católica do RS. Professora no Fundação Escola da Magistratura do Rio Grande do Sul e Escola Superior da Magistratura Federal. Advogada sócia do Escritório Mielke \& Lucena Advogados Associados. E-mail: jaqueline@mielkelucena. com.br. 
La Revista Chilena de Derecho del Trabajo y de la Seguridad Social es una publicación semestral del Departamento de Derecho del Trabajo y de la Seguridad Social de la Facultad de Derecho de la Universidad de Chile, y que tiene por objetivo el análisis dogmático y científico de las instituciones jurídico-laborales y de seguridad social tanto nacionales como del derecho comparado y sus principales efectos en las sociedades en las que rigen.

\author{
DIRECTOR \\ Luis Lizama Portal \\ EDITOR \\ Claudio Palavecino Cáceres \\ SECRETARIO DE REDACCIÓN \\ Eduardo Yañez Monje \\ SITIO WEB \\ revistatrabajo.uchile.cl \\ CORREO ELECTRÓNICO \\ pyanez@derecho.uchile.cl \\ LICENCIA DE ESTE ARTÍCULO \\ Creative Commons Atribución Compartir Igual 4.o Internacional
}

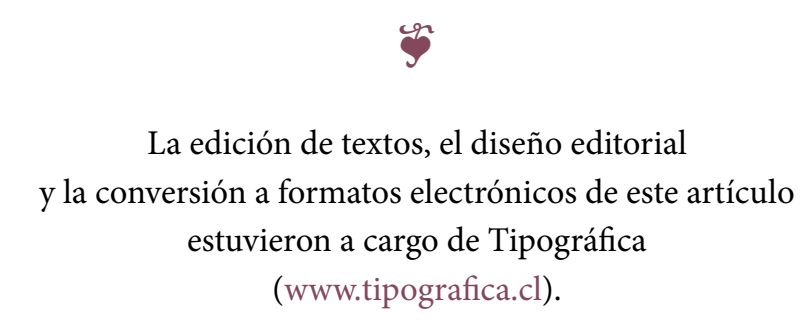

